\title{
Mechanistic modeling of cyclic voltammetry: A helpful tool for understanding biosensor principles and supporting design optimization
}

Semenova, Daria; Zubov, Alexandr; Silina, Yuliya E.; Micheli, Laura; Koch, Marcus; Fernandes, Ana C.; Gernaey, Krist V.

Published in:

Sensors and Actuators B: Chemical

Link to article, DOI:

10.1016/j.snb.2017.12.088

Publication date:

2018

Document Version

Peer reviewed version

Link back to DTU Orbit

Citation $(A P A)$ :

Semenova, D., Zubov, A., Silina, Y. E., Micheli, L., Koch, M., Fernandes, A. C., \& Gernaey, K. V. (2018).

Mechanistic modeling of cyclic voltammetry: A helpful tool for understanding biosensor principles and supporting design optimization. Sensors and Actuators B: Chemical, 259, 945-955.

https://doi.org/10.1016/j.snb.2017.12.088

\section{General rights}

Copyright and moral rights for the publications made accessible in the public portal are retained by the authors and/or other copyright owners and it is a condition of accessing publications that users recognise and abide by the legal requirements associated with these rights.

- Users may download and print one copy of any publication from the public portal for the purpose of private study or research.

- You may not further distribute the material or use it for any profit-making activity or commercial gain

- You may freely distribute the URL identifying the publication in the public portal 


\section{Accepted Manuscript}

Title: Mechanistic modeling of cyclic voltammetry: A helpful tool for understanding biosensor principles and supporting design optimization

Authors: Daria Semenova, Alexandr Zubov, Yuliya E. Silina, Laura Micheli, Marcus Koch, Ana C. Fernandes, Krist V.

Gernaey

PII:

S0925-4005(17)32414-0

DOI: $\quad$ https://doi.org/10.1016/j.snb.2017.12.088

Reference: $\quad$ SNB 23776

To appear in: $\quad$ Sensors and Actuators B

Received date: $\quad 14-11-2017$

Revised date: $\quad 12-12-2017$

Accepted date: $\quad 14-12-2017$

Please cite this article as: Daria Semenova, Alexandr Zubov, Yuliya E.Silina, Laura Micheli, Marcus Koch, Ana C.Fernandes, Krist V.Gernaey, Mechanistic modeling of cyclic voltammetry: A helpful tool for understanding biosensor principles and supporting design optimization, Sensors and Actuators B: Chemical https://doi.org/10.1016/j.snb.2017.12.088

This is a PDF file of an unedited manuscript that has been accepted for publication. As a service to our customers we are providing this early version of the manuscript. The manuscript will undergo copyediting, typesetting, and review of the resulting proof before it is published in its final form. Please note that during the production process errors may be discovered which could affect the content, and all legal disclaimers that apply to the journal pertain. 


\title{
Mechanistic modeling of cyclic voltammetry: a helpful tool for understanding biosensor principles and supporting design optimization
}

\author{
Authors \\ Daria Semenova ${ }^{\mathrm{a}, *}$, Alexandr Zubov ${ }^{\mathrm{a}}$, Yuliya E. Silina ${ }^{\mathrm{b}}$, Laura Michelic, Marcus Koch ${ }^{\mathrm{b}}$, Ana C. Fernandes ${ }^{\mathrm{a}}$, Krist V. Gernaey ${ }^{\mathrm{a}}$ \\ a Process and Systems Engineering Center (PROSYS), Department of Chemical and Biochemical Engineering, Technical University of \\ Denmark, Søltofts Plads, Building 229, 2800 Kgs. Lyngby, Denmark \\ b INM - Leibniz Institute for New Materials, Campus D2 2, 66123 Saarbrücken, Germany

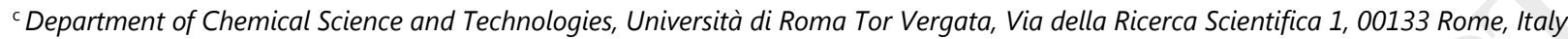 \\ ${ }^{*}$ Corresponding author. \\ E-mail address: dsem@kt.dtu.dk (D. Semenova).
}

\section{Highlights}

- The physicochemical parameters required for mathematical modeling were either found in literature or estimated on the basis of experimental data. Thus, the applicability of the developed model is not limited by the dataset or biosensor design.

- The developed cyclic voltammetry simulator was applied for interpreting the experimental results at various mediator concentrations, membrane thickness/compositions and operating conditions of the proposed multi-layer biosensor system.

- An accurate electrochemical, morphological and microscopic characterization of the biosensor system coupled with the model predictions allowed to identify the parameters crucial for the stable biosensor response.

- Based on the model predictions, a more favourable design of the biosensor system was developed, which subsequently reduced the reagent usage and waste generation.

\footnotetext{
Abstract

Design, optimization and integration of biosensors hold a great potential for the development of cost-effective screening and point-ofcare technologies. However, significant progress in this field can still be obtained on condition that sufficiently accurate mathematical models will be developed. Herein, we present a novel approach for the improvement of mechanistic models which do not only combine the fundamental principles but readily incorporate the results of electrochemical and morphological studies. The first generation glucose biosensors were chosen as a case study for model development and to perform cyclic voltammetry (CV) measurements. As initial step in the model development we proposed the interpretation of experimental voltammograms obtained in the absence of substrate (glucose). The model equations describe dynamic diffusion and reaction of the involved species (oxygen, oxidized/reduced forms of the mediator Prussian Blue/Prussian White). Furthermore, the developed model was applied under various operating conditions as a crucial tool for biosensor design optimization. The obtained qualitative and quantitative dependencies towards amperometric biosensors design
} 
optimization were independently supported by results of cyclic voltammetry and multi-analytical studies, such as scanning electron microscopy (SEM), energy dispersive X-ray spectroscopy (EDX) and liquid chromatography-electrospray ionization-tandem mass spectrometry (LC-ESI-MS/MS). Remarkably, a linear response of the optimized biosensors tested at the applied voltage (-0.14 V) in the presence of the glucose was obtained from $10^{-3}$ to $10^{-5} \mathrm{M}$ (relative standard deviation (RSD) < $7 \%$ per electrode). We believe that the presented model can be used to determine the exact mechanism driving the electrochemical reactions and to identify critical system parameters affecting the biosensor response that would significantly contribute to the knowledge on biosensing, device's design and bioengineering strategies in the future.

\section{Keywords}

Mechanistic Modeling, Cyclic Voltammograms, Amperometric Biosensors, Glucose Biosensors, SEM/EDX, LC-ESI-MS/MS.

\section{Introduction}

The development of a crucial tool for an accurate and reliable diagnostics and continuous monitoring of glucose concentrations, mainly for diabetes patients, resulted in more than 50 years of research and the establishment of the amperometric glucose sensors in clinical diagnostics [1,2]. Being compact, relatively stable and cheap, biosensors nowadays found their application in medicine [3,4], pharmacology [5], microbiology [6], the food industry [7], defense technologies [8] and others. Moreover, glucose biosensors hold a great potential for glucose monitoring in fermentation processes $[9,10]$ addressing the needs within biotechnological strain development. However, the reliability of the biosensor response in the continuous monitoring is still a limiting factor for their further integration in biotechnology.

Common detection techniques applied to biosensors, such as electrochemical impedance spectroscopy (EIS), chronoamperometry (AM) and cyclic voltammetry (CV), allow getting more detailed insights into the principles of sensing mechanisms [11]. In order to get a better understanding of the nature of the electrode reactions and to improve the biosensor performance, mathematical models were applied to electrochemical biosensors [12]. The first model for the amperometric response of an enzyme electrode for the glucose - glucose oxidase system was presented by Mell and Maloy [13] in the seventies, after Guilbault and Lubrano [14] constructed an amperometric glucose sensitive electrode. The first theoretical treatment of the cyclic voltammograms was presented by Nicholson and Shain [15]. In their work, the reversible and irreversible charge transfer mechanisms were coupled with homogenous first order chemical or electrochemical reactions. Moreover, the analytical solution was also presented for the electrochemical reaction followed by the mediated enzyme reaction. A commercially available simulation program for cyclic voltammetry, DigiSim (Bioanalytical Systems, West Lafayette, IN), developed by Feldberg and Rudolph [16] describes the electrochemical reactions coupled with first- and/or second-order chemical reactions. However, the mechanism of the enzymatic reactions is very complex and the assumption that the kinetics obey a first-order reaction can only be applied in very rare cases. Yokoyama and Kayanuma [17] developed a cyclic voltammetry simulator for electrochemically mediated enzyme reactions for various mediator and substrate concentrations, therefore not being limited by first- or pseudo-first-order reaction kinetics. The presented model allowed determining the kinetic constants for the homogeneous reaction between glucose oxidase (GOx) and glucose in the presence of ferrocene derivatives. Later on, the model principles were applied for modeling the reversible electrochemical reaction with one electron followed by the mediated reaction of immobilized enzyme with two electrons [18]. The simulation of cyclic voltammetry was also applied for studying the influence of ohmic drop [19,20], electrode area, electrochemical reaction constants and transferring coefficients [21], as well as the effect of flow rates [22-24] on the current response and wave shape. Analyzing the curve shape, peak shifts and amplitudes between the first cycle and successive scans in the obtained cyclic voltammograms is an important key in providing useful information on the mechanism of the electrochemical reaction as well as the adsorption mechanism and the diffusivities of the electrochemical species [25]. All these experimental data make CV a powerful analytical tool to identify the correlations between the sensor morphology and system parameters, underlying the desired biosensor response. However, only the works of Cannes et al. [26,27] demonstrated how the analytical techniques, such as CV measurements and scanning electrochemical microscopy (SECM), can be combined with simple numerical simulations for quantitative estimation of biosensor system parameters.

The general idea underlying this study is the development of a novel mathematical tool for amperometric biosensor operation and design optimization. To achieve this goal, we have used, as a first step, the combination of a mechanistic model for cyclic voltammograms with experimental multi - analytical studies. As a case study, the biosensor design with enhanced stability was adopted from the works of Ricci et al. [28,29]. The surface of the working electrode (WE) of commercially available screen-printed electrodes was chemically modified with a hydrogen peroxide sensitive catalyst, Prussian Blue [30], and covered with an enzyme/membrane layer (see Figure S1, Supplementary Materials). The experimental voltammograms were compared with simulation results, which allowed to use the formulated model not only for studying the processes occurring inside the biosensor system, but also to identify the critical system parameters. The results of the model predictions were fully supported by subsequent electrochemical (CV), bioanalytical (LC-ESI-MS/MS, EDX) and morphological (SEM) studies. 


\section{Mathematical Modeling}

2.1 .

Computational Domain and Governing Equations

The main objective of the model was to predict cyclic voltammetry curves for the reversible electrochemical reaction coupled with oxidation/reduction of the catalyst in the absence of substrate (glucose) for an air saturated phosphate buffer solution, at different operating conditions. The biosensor was modeled spatially as a one-dimensional system. Non-linear second order partial differential equations combine the dynamic diffusion and reaction of the involved chemical species in the enzymatic/membrane layer, as well as electrochemical reaction on the surface of the electrode. Different regions of the multi-layer glucose biosensor system (electrode surface, enzyme/membrane layer and stagnant diffusion layer) were associated with diffusion fluxes, chemical and electrochemical reactions (see Figure S2, Supplementary Materials). It was assumed that the oxidized form ( $M_{\text {ox }}$ ) of artificial peroxidase - Prussian Blue (PB), was deposited on the surface of the working electrode, whereas the reduced form (Mred) - Prussian White (PW), was produced during the reversible two - electron transfer reaction [31] (note that the PB/PW abbreviation is simplified to Mox/Mred since historically Prussian Blue was called a "mediator" in the literature):

$\mathrm{M}_{\text {(ox) }}^{\text {insoluble }}+2 e^{-} \frac{k_{(\mathrm{red})}}{k_{(\mathrm{ox})}} \mathrm{M}_{(\mathrm{red})}$

The complete reduction of molecular oxygen in the presence of Prussian White was described as a four - electron transfer reaction taking place inside of the enzyme/membrane layer [32]:

$$
\mathrm{O}_{2}+\mathrm{M}_{(\mathrm{red})} \stackrel{\mathrm{k}_{1}}{\longrightarrow} \mathrm{M}_{(\mathrm{ox})}+4 e^{-}+\mathrm{H}_{2} \mathrm{O}
$$

The kinetics of the electrochemical reactions were assumed to be fully reversible, whereas the oxygen reduction followed a second order kinetics. Considering one-dimensional diffusion, the governing equations for oxygen (1), (4), oxidized (2) and reduced (3) forms of the mediator were formulated as follows:

Enzyme/membrane layer, $\mathrm{t}>0$, and $0<\mathrm{x}<\mathrm{d}_{\mathrm{e}}$ :

$$
\begin{gathered}
\frac{\partial\left[O_{2}\right]}{\partial t}=D_{O_{2, e}} \frac{\partial^{2}\left[O_{2}\right]}{\partial x^{2}}-r\left(\left[O_{2}\right],\left[M_{r e d}\right]\right) \\
\frac{\partial\left[M_{o x}\right]}{\partial t}=D_{M_{o x, e}} \frac{\partial^{2}\left[M_{o x}\right]}{\partial x^{2}}+r\left(\left[O_{2}\right],\left[M_{r e d}\right]\right) \\
\frac{\partial\left[M_{r e d}\right]}{\partial t}=D_{M_{r e d, e}} \frac{\partial^{2}\left[M_{r e d}\right]}{\partial x^{2}}-r\left(\left[O_{2}\right],\left[M_{r e d}\right]\right)
\end{gathered}
$$

Diffusion layer, $\mathrm{t}>0$, and $\mathrm{d}_{\mathrm{e}}<\mathrm{x}<\mathrm{d}_{\mathrm{e}}+\mathrm{d}_{\mathrm{d}}$ :

$$
\frac{\partial\left[O_{2}\right]}{\partial t}=D_{O_{2, d}} \frac{\partial^{2}\left[O_{2}\right]}{\partial x^{2}}
$$

where $D_{O_{2, e}}$ and $D_{O_{2, d}}$ are diffusion coefficients for the oxygen inside the enzyme/membrane and diffusion layers, respectively. Inside the enzyme/membrane layer, $D_{M_{r e d, e}}$ and $D_{M_{o x, e}}$ refer to the diffusion coefficients of the reduced and oxidized form of the mediator, respectively. The thickness of the enzyme/membrane layer was set as $d_{e}$, whereas for the diffusion layer it was $d_{d}$. The mediator layer thickness was neglected in the model, assuming that PB crystals are adsorbed inside the cavities of the graphene oxide layer surface (see Figure S3, Supplementary Materials). The rate $(r)$ of the homogeneous reaction (5) between the reduced form of the mediator and oxygen is provided in the equation below:

$$
r\left(\left[O_{2}\right],\left[M_{\text {red }}\right]\right)=k_{1} \cdot\left[O_{2}\right] \cdot\left[M_{\text {red }}\right]
$$

where $k_{1}$ is a kinetic constant for the complete PW oxidation in the presence of oxygen for air saturated solutions [32].

\subsection{Initial and Boundary Conditions}

The zero mediator concentration inside the enzyme/membrane layer (6), as well as the oxygen absence (7) inside the diffusion and enzyme/membrane layers, were set as the initial conditions of the model following the equations below:

$t=0$, and $0<x<d_{e} \quad\left[M_{\text {ox }}\right]=\left[M_{\text {red }}\right]=0$ 
$t=0$, and $0<x<d_{e}+d_{d}$

$$
\left[O_{2}\right]=0
$$

The boundary conditions for oxygen dissolved in the bulk solution (8), the continuity of oxygen diffusion fluxes at the interface between the enzyme/membrane and diffusion layer (9) and the zero oxygen flux at the electrode surface (10) were set in the model as follows:

$t>0$, and $x=d_{e}+d_{d}$

$t>0$, and $x=d_{e}$

$$
\left[O_{2}\right]=\left[O_{2, \text { bulk }}\right]
$$$$
D_{O_{2, e}} \frac{\partial\left[O_{2}\right]}{\partial x}=D_{O_{2, d}} \frac{\partial\left[O_{2}\right]}{\partial x}
$$

$t>0$, and $x=0$

$$
D_{O_{2, e}} \frac{\partial\left[O_{2}\right]}{\partial x}=0
$$

The zero mediator concentration at the boundary of the enzyme/membrane layer (11) and the concentration ratio between oxidized and reduced forms of the mediator controlled by the Nernst equation at the electrode surface (12) were given by:

$t>0$, and $x=d_{e}$

$$
\left[M_{o x}\right]=\left[M_{\text {red }}\right]=0
$$

$t>0$, and $x=0$

$$
\frac{\left[M_{o x}\right]}{\left[M_{\text {red }}\right]}=\exp \left\{\frac{n_{e} \cdot F}{R \cdot T} \cdot\left(E-E^{0}\right)\right\}
$$

where $n_{e}$ is a number of electrons involved in a charge transfer, $F$ is the Faraday constant, $R$ represents the universal gas constant, $T$ is temperature, $E$ is the applied potential vs. the reference electrode and $E^{0}$ is the standard potential. The biosensor response (13), measured as the current as a function of time, $i(t)$, was governed by:

$$
i(t)=n_{e} \cdot A \cdot F \cdot D_{M_{r e d, e}} \cdot \frac{\partial\left[M_{r e d}\right]}{\partial x}
$$

where $A$ is the surface area of the working electrode.

\subsection{Model Implementation}

The governing model equations were discretized by the finite difference method (FDM) and numerically solved using an explicit Euler scheme. The proposed model for cyclic voltammetry responses was implemented in both MATLAB ${ }^{\circledR}$ and FORTRAN languages. Following the IUPAC recommendation, the arising positive current in the voltammogram corresponds to the oxidation process (anodic current), whereas the negative current represents the reduction process (cathodic current).

The major part of the physicochemical parameters required for the mathematical model was found in the literature (Table 1). The mediator concentration and standard redox potential values had to be adjusted based on the difference between the fabrication procedures of biosensor systems (values are also presented in Table 1). The thickness of the enzyme/membrane layer was estimated from SEM analysis presented in section 4.3. The thickness of the diffusion layer was set as $1 \mu \mathrm{m}$ in all simulations.

Table 1 - Values of the biosensor system parameters used in simulations

\begin{tabular}{c|c|c|c}
\hline Parameter & Description & Model value & Reference \\
\hline$D_{O_{2, e}}\left[\mathrm{~m}^{2} / \mathrm{s}\right]$ & $\begin{array}{c}\text { Diffusivity of oxygen in polymeric } \\
\text { membrane }\end{array}$ & $5.0 \times 10^{-12}$ & [33] \\
\hline$D_{M_{o x, e}}\left[\mathrm{~m}^{2} / \mathrm{s}\right]$ & $\begin{array}{c}\text { Diffusivity of oxidized form of } \\
\text { mediator in polymeric membrane }\end{array}$ & $10.0 \times 10^{-14}$ & {$[34,35]$} \\
\hline$D_{M_{\text {red,e }}}\left[\mathrm{m}^{2} / \mathrm{s}\right]$ & $\begin{array}{c}\text { Diffusivity of reduced form of } \\
\text { mediator in polymeric membrane }\end{array}$ & $7.0 \times 10^{-13}$ & {$[33]$} \\
\hline$D_{O_{2, d}}\left[\mathrm{~m}^{2} / \mathrm{s}\right]$ & Diffusivity of oxygen in diffusion layer & $2.0 \times 10^{-09}$ & {$[32]$} \\
\hline$k_{1}\left[\mathrm{M}^{-1} \mathrm{~s}^{-1}\right]$ & $\begin{array}{r}\text { Kinetic constant for the oxygen } \\
\text { reduction by PB }\end{array}$ & 0.107 & {$[36,37]$} \\
\hline$n_{e}$ & $\begin{array}{r}\text { Electrons involved in the PB redox } \\
\text { reaction }\end{array}$ & 2 & {$[38]$} \\
\hline$O_{2}\left[\mathrm{~mol} / \mathrm{m}^{3}\right]$ & Oxygen concentration dissolved in & 0.271563 & \\
\hline
\end{tabular}




\begin{tabular}{c|c|c|c}
\hline & water & & \\
\hline$M_{o x}\left[\mathrm{~mol} / \mathrm{m}^{3}\right]$ & $\begin{array}{c}\text { Prussian Blue concentration deposited } \\
\text { over WE }\end{array}$ & $5 / 20 / 100$ & experiment \\
\hline$E^{0}[\mathrm{~V}]$ & $\begin{array}{c}\text { Standard Potential } \\
\text { PW/PB redox couple }\end{array}$ & $0.13 /-0.05$ & CV experiment \\
\hline$d_{e}[\mathrm{~m}]$ & $\begin{array}{c}\text { Thickness of the enzyme/membrane } \\
\text { layer }\end{array}$ & $7.0 \times 10^{-06}$ & SEM experiment \\
\hline$d_{d}[\mathrm{~m}]$ & Thickness of the diffusion layer & $1.0 \times 10^{-06}$ & estimation \\
\hline$A\left[\mathrm{~m}^{2}\right]$ & Surface area of the working electrode & $1.257 \times 10^{-05}$ & experiment \\
\hline$T[\mathrm{~K}]$ & Temperature & 298.15 & experiment \\
\hline
\end{tabular}

\section{Experimental Section}

\subsection{Materials and reagents}

Screen printed electrodes (SPES) DRP-PW-110DGPHOX were customized by DropSens (Llanera, Spain). The electrodes were printed on polyester substrate and each sensor consists of a carbon working electrode modified with graphene oxide, a carbon counter electrode and a silver reference electrode. The diameter of the working electrode was $0.4 \mathrm{~cm}$, resulting in an apparent geometric area of $0.126 \mathrm{~cm}^{2}$. Glucose oxidase (GOx) (EC 1.1.3.4, type VII, $248 \mathrm{U} / \mathrm{g}$ solid) and bovine serum albumin (BSA) were obtained from Sigma (St. Louis, MO, USA). Glutaraldehyde solution $(25 \%(\mathrm{v} / \mathrm{v})$ ), ethanol (UV HPLC gradient, 99.9\%) and potassium hexacyanoferrate (III) (ACS reagent, $\geq 99.0 \%$ ) were purchased from Sigma - Aldrich (St. Louis, MO, USA). Iron (III) chloride (anhydrous, 99.99\%) and Nafion ${ }^{\circledR} 117$ solution $(\sim 5 \%(\mathrm{v} / \mathrm{v})$ in a mixture of lower aliphatic alcohols and water) were provided by Aldrich (Steinheim, Germany). D-Glucose (anhydrous) was provided by Fluka (Loughborough, UK). Mono - and di-potassium hydrogen phosphates (anhydrous) were obtained from Merck (Darmstadt, Germany). Sodium hydroxide $(50 \%(\mathrm{w} / \mathrm{w}))$ and hydrochloric acid $(37 \%(\mathrm{w} / \mathrm{w}))$ solutions were purchased from VWR International A/S (Søborg, Denmark). All the solutions were prepared with $0.1 \mathrm{M}$ phosphate buffer supplemented with $0.1 \mathrm{M} \mathrm{KCl}$ $(\mathrm{pH}=6)$, unless stated otherwise.

\subsection{Glucose biosensor preparation \\ Preparation method 1:}

The chemical deposition procedure of PB was adopted from works of Ricci et al. [29]. A $10 \mu \mathrm{L}$ drop (total volume) of freshly made precursor solution, containing $0.1 \mathrm{M}$ potassium ferrocyanide $\left(\mathrm{K}_{3} \mathrm{Fe}(\mathrm{CN})_{6}\right)$ in $10 \mathrm{mM} \mathrm{HCl}$ mixed with $0.1 \mathrm{M}$ ferric chloride $\left(\mathrm{FeCl}_{3}\right)$ solution in $10 \mathrm{mM} \mathrm{HCl}(1: 1$ proportion $(\mathrm{v} / \mathrm{v}))$, was directly placed over the working electrode (WE) surface of the SPEs. The sensors were left to dry for 15 (sensor 1) or 40 (sensor 2) minutes at room temperature and then washed with a $10 \mathrm{mM} \mathrm{HCl}$ solution and deionized water. In order to stabilize the PB layer, the sensors were placed in the oven at $100^{\circ} \mathrm{C}$ for $2 \mathrm{~h}$. Prior to glucose oxidase (GOx) immobilization, a $2.5 \mu \mathrm{L}$ droplet of freshly prepared glutaraldehyde solution ( $1 \%(\mathrm{v} / \mathrm{v})$ diluted in water) was placed over the WE of the PB modified SPES and was left to dry at room temperature for $30 \mathrm{~min}$. After the glutaraldehyde solution layer was dried, the enzyme/membrane layer was deposited. The fresh enzyme/membrane solution was made by mixing GOx solution (53.7 U in phosphate buffer), BSA (5 vol. \% diluted in water) and Nafion ${ }^{\circledR} 117(0.2 \mathrm{vol}$. \% diluted in water) in a 1:1:1 proportion (v/v/v). A drop of $3 \mu \mathrm{L}$ of the final solution was placed over the working electrode of the PB/glutaraldehyde modified SPEs.

\section{Preparation method 2:}

In order to remove the impurities, the surfaces of all electrodes were pre-treated in a phosphate buffer solution under chronoamperometric conditions with applied potential of $+1.7 \mathrm{~V}$. The chronoamperometric measurement was performed using MultiEmStat (PalmSens, Utrecht, The Netherlands) with a DRP-CAST1X8 interface (DropSens, Llanera, Spain) controlled by MultiTrace 3.4 software (PalmSens, Utrecht, The Netherlands). After the stable current curve was obtained, the surface of the working electrode was modified with a Prussian Blue (PB) layer. The PB chemical deposition procedure presented in preparation method 1 was modified. Thus, a $5 \mu \mathrm{L}$ drop of $0.1 \mathrm{M}$ solution of potassium ferrocyanide $\mathrm{K}_{3} \mathrm{Fe}(\mathrm{CN})_{6}$ in $10 \mathrm{mM} \mathrm{HCl}$ was placed over the working electrode and mixed with a $5 \mu \mathrm{L}$ drop of $0.1 \mathrm{M}$ solution of ferric chloride, $\mathrm{FeCl}_{3}$ in $10 \mathrm{mM} \mathrm{HCl}$ directly on the surface of the electrode. The sensors were left to dry for $40 \mathrm{~min}$ at room temperature and then washed with a $10 \mathrm{mM} \mathrm{HCl}$ solution, deionized water and dried with air. In order to stabilize the PB layer, the sensors were placed in the oven at $100^{\circ} \mathrm{C}$ for $1 \mathrm{~h}$. Similar to preparation method 1 , the surface of WE for PB modified SPEs was pretreated with glutaraldehyde solution prior to enzyme/membrane layer deposition. In contrast to preparation method 1, Nafion ${ }^{\circledR} 117$ (2 vol. \%) neutralized in ethanol [39] was mixed with GOx solution (53.7 U in phosphate buffer) and BSA (5 vol. \% diluted in water) in a 1:1:1 proportion ( $\mathrm{v} / \mathrm{v} / \mathrm{v})$. A drop of $3 \mu \mathrm{L}$ of final solution was placed over the working electrode of the $\mathrm{PB} /$ glutaraldehyde modified SPEs, yielding sensor 3 batch.

Regardless of the preparation method, sensors with deposited enzyme/membrane layer were placed to dry overnight in a climate chamber at $40 \%$ of humidity and $8^{\circ} \mathrm{C}$. Moreover, both PB modified SPEs and complete glucose biosensors were stored in the dark, at room temperature and $4^{\circ} \mathrm{C}$, respectively.
3.3.
Glucose Oxidase activity measurement 
The GOx activity measurement prior to the immobilization step of the stock solutions, as well as the enzyme/membrane mixtures, was performed by using an OXSOLV solvent-resistant, fiber - optic oxygen sensor (Pyro Science GmbH, Aachen, Germany) connected to a FireStingO2 fiber - optic meter (Pyro Science GmbH, Aachen, Germany) and controlled by Pyro Oxygen Logger software (Pyro Science $\mathrm{GmbH}$, Aachen, Germany). The measurement was based on on-line monitoring of the dissolved oxygen (DO) consumption in the reaction of GOx with $100 \mathrm{mM}$ glucose solution at room temperature (see Figure S4, Supplementary Materials). The set - up assembly, as well as the experimental procedure, were adopted from the works of Bolivar et al. [40,41]. A glass beaker with a liquid working volume of $10 \mathrm{~mL}$ and a magnetic stirrer $(10 \times 5 \mathrm{~mm})$ were used for the experiments. The magnetic stirring was performed at $600 \mathrm{rpm}$ (IKA® RET Basic, Staufen im Breisgau, Germany). The $100 \mu \mathrm{L}$ of glucose solution was dissolved in $7 \mathrm{~mL}$ of buffer solution. The oxidation reaction was initialized by addition of different volumes of the GOx stock solution or the enzyme/membrane mixtures after the value of DO was stabilized. For the enzyme activity calculations, one unit $(U)$ of enzyme corresponds to a substrate consumption of $1 \mu$ mol per min. The GOx activity in the enzyme/membrane mixture prior to immobilization was estimated as $0.179 \mathrm{U} / \mu \mathrm{L}$.

3.4 .

Cyclic voltammetry behavior of glucose biosensors in phosphate buffer

Cyclic voltammetry (CV) measurements were performed using MultiEmStat (PalmSens, Utrecht, The Netherlands) with a DRP-CAST1X8 interface (DropSens, Llanera, Spain) controlled by MultiTrace 3.4 software (PalmSens, Utrecht, The Netherlands). A $100 \mu \mathrm{L}$ droplet of phosphate buffer was placed over all three electrodes of SPE. The voltammograms were recorded at different scan rates in a potential range from $-0.5 \mathrm{~V}$ to $+0.5 \mathrm{~V}$. After each run sample droplets were collected for subsequent LC-ESI-MS/MS analysis.

3.5. Biosensor sensitivity determination

In order to estimate the sensitivity of the developed biosensors, chronoamperometric studies were carried out in the presence of glucose solutions (concentration range: $10^{-7}-10^{-3} \mathrm{M}$ ) at the applied voltage equal to the peak potential of the reduction curve $(-0.14 \mathrm{~V})$. Moreover, the biosensors were characterized in the presence of the analytical range of glucose concentrations ( 0.1 to $2 \mathrm{mM})$. All measurements from the same biosensor were repeated at least in triplicates.

3.6. Scanning electron microscopy (SEM) and energy dispersive $X$-ray spectroscopy (EDX)

Micrographs of the bare and PB/(GOx + Nafion) modified SPEs were obtained by scanning electron microscopy (SEM) using a FEI (Hilsboro, OR, USA) Quanta $400 \mathrm{FEG}$, operating at $10 \mathrm{kV}$ accelerating voltage. Secondary (SE) and backscattered (BSE) electron images were collected in low vacuum mode $\left(\mathrm{pH}_{2} \mathrm{O}=100 \mathrm{~Pa}\right)$. The microscope was equipped with an EDAX (Mahwah, NJ, USA) Genesis V6.04 energy dispersive X-ray (EDX) system in order to obtain information on elemental composition of the biosensor surfaces. The measuring time per sample was equal to $100 \mathrm{sec}$. In addition, the correlative SEM/EDX analysis allowed determining the composition of the multi-layer biosensor.

3.7. Liquid chromatography-electrospray ionization-tandem mass spectrometry (LC-ESI-MS/MS)

In order to verify the chemical stability of the biosensor layers deposited over the surface of the working electrode, liquid chromatography electrospray ionization tandem mass spectrometry (LC-ESI-MS/MS) was utilized. The HPLC analysis was performed on an Agilent Infinity 1260 series instrument (Agilent Technologies, CA, USA) coupled with a quadrupole time-of-flight mass spectrometer Q-TOF LC/MS 6545 (Agilent Technologies, CA, USA) equipped with Jet Stream Thermal Focusing Technology ESI source. The data acquisition was controlled by MassHunter Software Tools. For LC-ESI-MS/MS experiments, a $30 \mu \mathrm{L}$ water droplet spotted for 30 min on the glucose biosensors, previously not used in electrochemical studies, was taken. The obtained results were compared with data obtained in the LC-ESI-MS/MS study of buffer samples collected after each scan in CV. Chromatographic separation was achieved on the ZORBAX Eclipse Plus C 18 column $(2.1 \times 50 \mathrm{~mm}$, particles size $1.8 \mu \mathrm{m})$ (Agilent, CA, USA). The mobile phase consisting of $0.3 \%$ formic acid in water (Solvent $A$ ) and acetonitrile (Solvent B) was used in the following gradient elution step: 90\% Solvent A, was held for 2 min, then decreased to $10 \%$ in $9 \mathrm{~min}$ and held for $2 \mathrm{~min}$, and returned back to the starting conditions in $0.5 \mathrm{~min}$ for 8 min equilibration. The column operation temperature was fixed at $30^{\circ} \mathrm{C}$, the mobile phase flow rate was $0.3 \mathrm{~mL} / \mathrm{min}$ and the injection volume was $10 \mu \mathrm{L}$.

MS scans were performed in a negative ion mode, operating under capillary voltage at $4500 \mathrm{~V}$; the fragmentor voltage was set at $70 \mathrm{eV}$; dry gas temperature at $350^{\circ} \mathrm{C}$; gas flow at $9 \mathrm{~L} / \mathrm{min}$; nebulizing gas pressure at $45 \mathrm{psi}$. The mass spectra for all samples were recorded at $\mathrm{m} / \mathrm{z}$ 100-1500. The MS/MS experiments were conducted in product ion scan mode at collision energies ranging from 10 to $50 \mathrm{eV}$. The elemental compositions were identified based on the accurate mass measurements and data processing of total ion chromatograms (TICs) of the parent ions and fragments obtained in the MS/MS experiments.

\section{Results and Discussion}

\subsection{Mathematical Model Validation}

The initial design of the glucose biosensor system was based on the preparation method 1 . In Figure 1 a good qualitative response of the numerical solutions is presented together with the experimental voltammograms obtained at $50 \mathrm{mV} / \mathrm{sec}$ for the two types of glucose biosensors with different PB modification time. 


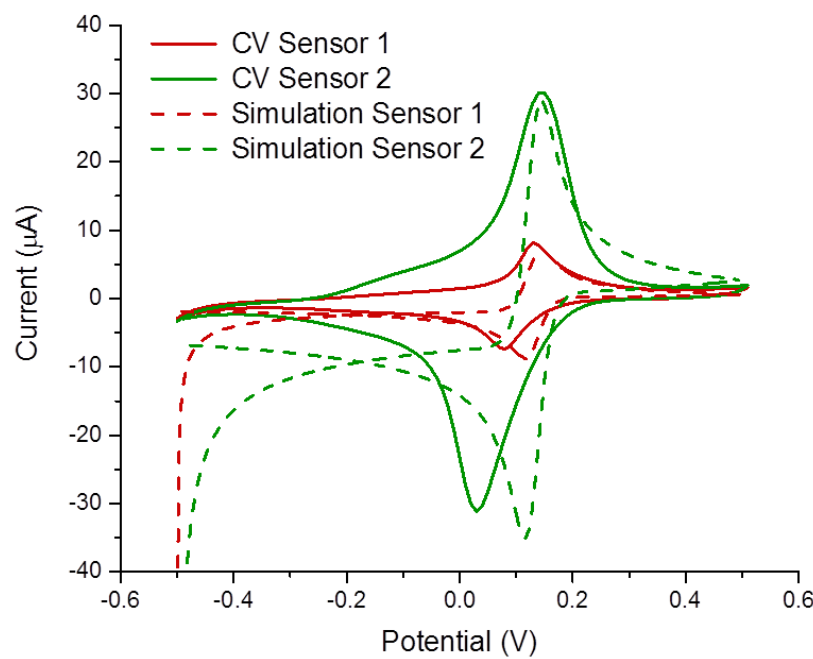

Figure 1 - Comparison of the model output (dashed line) vs. experimental data (solid line) for two types of glucose biosensor fabricated according to preparation method 1: sensor 1 represents the results of $15 \mathrm{~min}$ PB deposition time, whereas sensor 2 refers to the 40 min procedure. The presented voltammograms were recorded/simulated for $50 \mathrm{mV} / \mathrm{sec}$ scanning speed.

In both simulations, the initial value for the deposited PB had to be adjusted for the two different types of biosensor: for sensor 1 the concentration of the deposited oxidized form of mediator $\left(M_{\circ x}\right)$ was estimated as $5 \mathrm{mM}$, whereas for sensor 2 this parameter value was equal to $20 \mathrm{mM}$. From Figure 1 it is clear that no significant quantitative response can be obtained for the reduction curve, especially in case of higher mediator loadings. In order to validate the developed model, an additional set of experiments for the glucose biosensors was proposed. The sensor 2 type was tested at a potential range from $-0.5 \mathrm{~V}$ to $+0.5 \mathrm{~V}$ with higher scan rates: from 100 to $500 \mathrm{mV} / \mathrm{sec}$. The obtained voltammograms were compared with the model output shown in Figure 2.

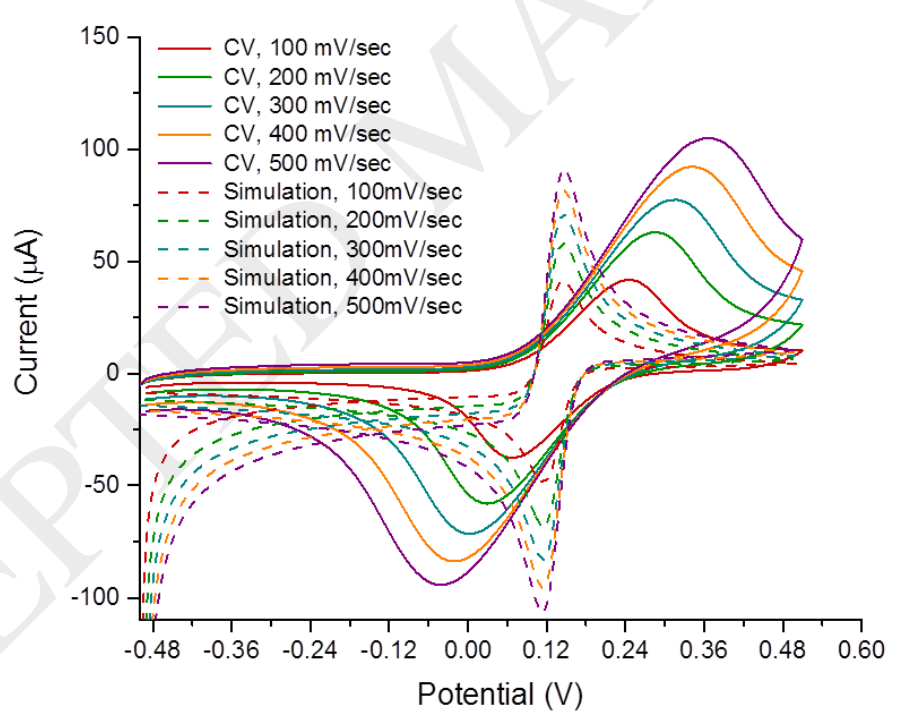

Figure 2 - The experimental voltammograms (solid line) vs. the model output (dashed line). Glucose biosensors were cycled at different scan rates $(100$ to $500 \mathrm{mV} / \mathrm{sec})$.

The results presented in Figure 2 clearly demonstrated a strong disagreement between the model predictions and experimental data at high cycling speeds: no relevant peak potential shifts and peak current increase were obtained with the model. Therefore, it was concluded that the assumed mechanisms of chemical and physical processes taking place inside the biosensor system proposed in the model were not sufficient. However, the variation of model parameters, namely $\boldsymbol{d}_{\boldsymbol{e}}$ and $\boldsymbol{M}_{\boldsymbol{o x}}$ and further comparison of the simulation results with the experimental voltammograms allowed assuming that the irreversible changes occur inside the biosensor system. Thus, the disagreement between the model predictions and the experimental data was mainly attributed to the constant decrease in the thickness of the enzyme/membrane layer, as well as in the concentration of deposited mediator after each scan. Moreover, a reversible electron transfer behaviour estimated at the lower scans was not present in the experimental voltammograms obtained at cycling speeds higher than $50 \mathrm{mV} / \mathrm{sec}$. Varying the values of only two parameters $\left(\boldsymbol{d}_{\boldsymbol{e}}, \boldsymbol{M}_{\boldsymbol{o x}}\right)$ within the model allowed to 
understand better the additional processes taking place inside the biosensor, and to focus on the optimization of the PB deposition and membrane composition methods. In a subsequent part of the study the model was used to identify the crucial biosensor system parameters that were further optimized in a new preparation method for the glucose biosensors.

4.2. Biosensor Design Optimization

In order to achieve a reproducible response and improved stability of the biosensor system layers the preparation method 2 was proposed. In this procedure, two crucial aspects had to be fulfilled: first, to achieve a higher and stable loading of PB; and second, to guarantee the stability of the enzyme/membrane layer under different operating conditions. Therefore, the deposition procedure of the PB layer had to be modified together with the composition of the Nafion membrane. In order to avoid changes in the biosensor topology, such as mechanical decomposition of the PB and the membrane layer and its subsequent leakage, that effected the switch from reversible to irreversible electron transfer behavior of the biosensor system, the optimized biosensors from preparation method 2 (sensor 3 type) were cycled at scan rates lower than $50 \mathrm{mV} / \mathrm{sec}$. The potential range of the PB/PW redox couple from $-0.5 \mathrm{~V}$ to $+0.5 \mathrm{~V}$ was applied, as shown in Figure 3. Similar model parameters were used as for the simulations done for the preparation method 1 . The value for the concentration of the deposited PB and the standard redox potential were now fixed to $100 \mathrm{mM}$ and $-0.05 \mathrm{~V}$, respectively.

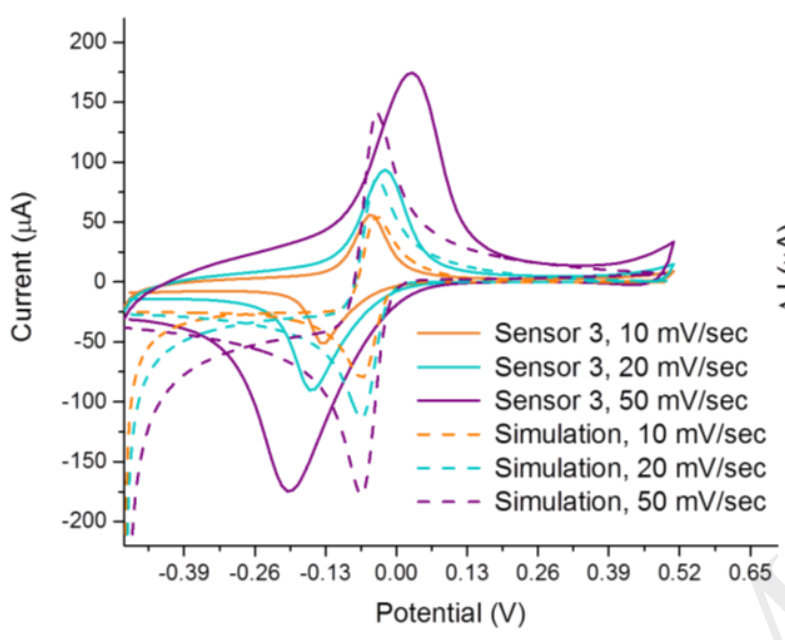

A

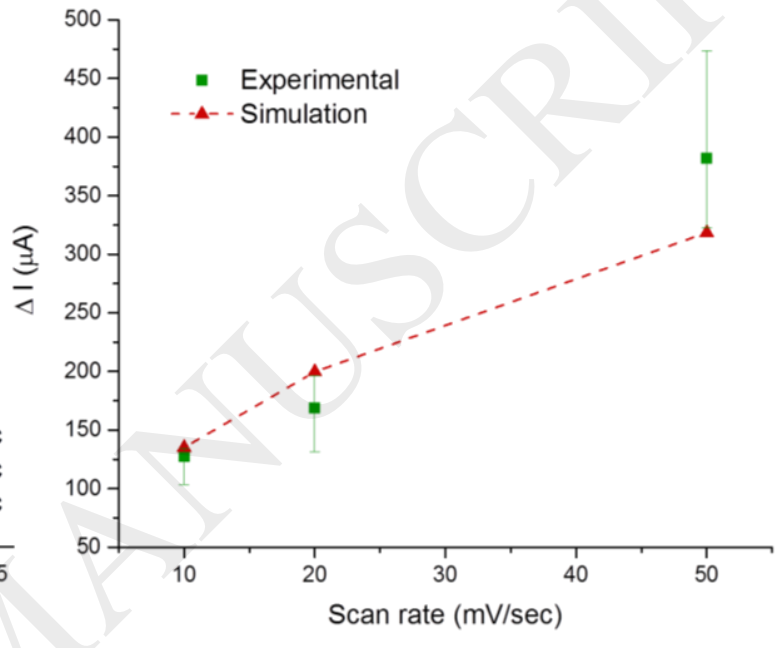

B

Figure 3 - Comparison of the experimental voltammograms obtained at the various scan rates for the optimized glucose biosensor design (preparation method 2) and the model output (A). The recorded difference of peak current values $(\Delta \mathrm{I}, \mu \mathrm{A})$ vs. scan rates is summarized in graph $B$, comparing experimental and simulation results.

The optimized method was analyzed for the sensor 3 type and the expected increase in the current response following the increase in the scan rates was obtained in all experiments for both oxidation and reduction processes (Figure 3B). Moreover, the simulated voltammograms presented in Figure 3A showed a fair agreement with the experimental curves, especially with respect to the peak current values. To study the influence of the scan rate and the amount of Nafion ${ }^{\circledR} 117$ present in the enzyme/membrane mixture on the stability of the biosensor layers and the response, PB modified SPEs from preparation method 2 were used to design sensor 4 type, where the preparation method 1 for the enzyme/membrane mixture was adapted. Thus, the principal difference between the sensor 3 and sensor 4 series was the composition and concentration of the Nafion membrane: $2.0 \%$ and $0.2 \%$ Nafion, respectively. The constructed glucose biosensors were tested for different scan rates and the results of electrochemical studies were further compared with the data obtained by liquid chromatography-electrospray ionization-tandem mass spectrometry (LC-ESI-MS/MS) and scanning electron microscopy (SEM) coupled with energy dispersive X-ray (EDX) analysis. The obtained results are presented in the following section 4.3 .

4.3.

The effect of the scan rate and membrane composition on the biosensor layers stability and response

Concerning the changes in the topology of the biosensor system from one scan to another in $\mathrm{CV}$, it was interesting to investigate the content of the buffer probes collected after each measurement by means of liquid chromatography tandem mass spectrometry (LCMS/MS). Therefore, the glucose biosensors from the sensor 3 and sensor 4 series were scanned at the potential range from $-0.5 \mathrm{~V}$ to $+0.5 \mathrm{~V}$ at 10, 20 and $50 \mathrm{mV} / \mathrm{sec}$ sweep speeds (see Figure S5, A, Supplementary Materials). Since no significant difference was obtained between the voltammograms for sensor 3 and sensor 4 designs, the probes were collected for 10 and $20 \mathrm{mV} / \mathrm{sec}$ scan rate experiments. To verify the correlation between the scan rate value or number of scans and the enzyme/membrane film stability, a fresh sensor was used for each scan rate. Moreover, to prove the influence of the electrochemical measurements on the biosensor layer stability one of 
the non-used glucose biosensors (sensor 3 and sensor 4 series) was tested in a steady state experiment with a water droplet. All the collected probes were investigated by subsequent LC-ESI-MS/MS analysis (Figure 4).
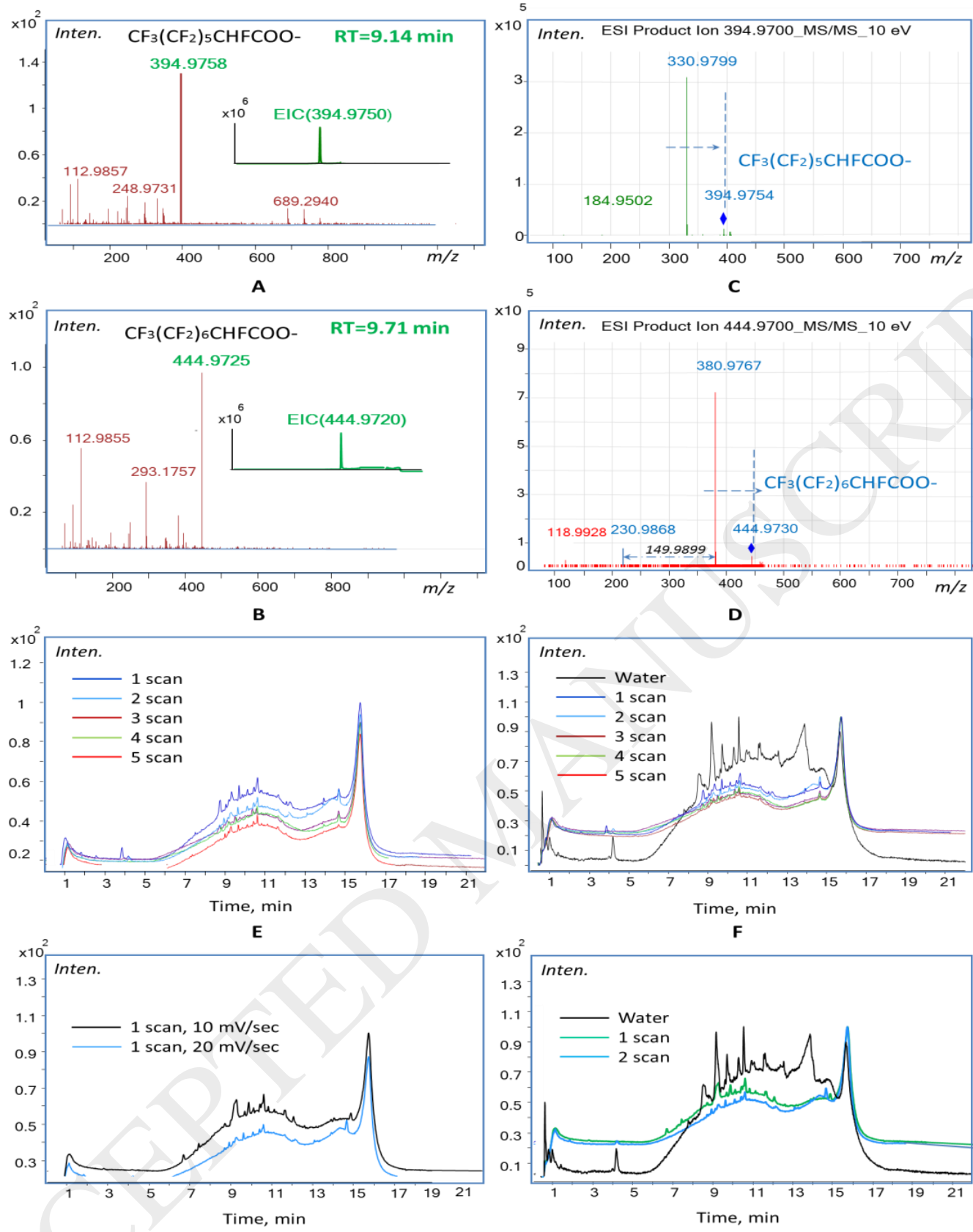

Figure 4 - Mass spectra (A-D), TIC and extracted ion chromatograms (EICs) (A,B) of buffer probes (coloured) and water droplets (black) of sensor $3(E-G)$ and sensor $4(H)$ series obtained for a different number of scans $(E)$ and sweep rates $(G)$. The results of the comparison of steady state experiment vs. CV probes collected for sensor 3 and sensor 4 series are presented in graphs $F$ and $H$, respectively. Nafion corresponding fragments in MS/MS spectra are shown at collision-induced dissociation (CID) experiments $10 \mathrm{eV}$.

In all samples tested by mass spectrometry the fragments corresponding to the Nafion membrane were clearly observed (Figure 4, A-D). The mass spectra were shown for perfluorinated carboxylic acids as the most environmentally persistent compounds of the Nafion fluoropolymer [42]. Thus, peaks at $m / z$ equal to 394.9758 and 444.9725 were tentatively identified as $\mathrm{CF}_{3}\left(\mathrm{CF}_{2}\right)_{5} \mathrm{CHFCOO}^{-}$and $\mathrm{CF}_{3}\left(\mathrm{CF}_{2}\right)_{6} \mathrm{CHFCOO}^{-}$fragments, respectively (Figure $\left.4 \mathrm{~A}, \mathrm{~B}\right)$. These structures were further confirmed by the major MS/MS fragments presented in Figure 4Figure $C$ and Figure 4D [43].

From the TIC chromatograms presented in Figure $4 \mathrm{E}$, it is clear that at low scan rates $(10 \mathrm{mV} / \mathrm{sec})$ the membrane layer (sensor 3 series, 2.0\% Nafion) stabilizes approximately at the fifth scan, whereas at $20 \mathrm{mV} / \mathrm{sec}$ (Figure $4 \mathrm{~F}$ ) the Nafion elution profile for 
the same type of membrane reaches a constant trend already at the third scan. The tendency of Nafion membrane stabilization at a higher sweeping speed was demonstrated for both probes collected after the first scans in Figure $4 \mathrm{G}$ and could also be traced in the voltammograms recorded at scan rates equal to 10 and $20 \mathrm{mV} / \mathrm{sec}$ (see Figure S5, B,C, Supplementary Materials). Comparing the elution profiles of Nafion-corresponded products, for probes collected after a steady state experiment and different scans in Figure $4 \mathrm{G}$ and Figure $4 \mathrm{H}$, it is clear that the CV measurements allow faster stabilization of the membrane layer regardless of its composition. Moreover, the concentration profiles of Nafion-corresponded products for the sensor 4 ( $0.2 \%$ Nafion) series tested at $20 \mathrm{mV} / \mathrm{sec}$ (see Figure S6, Supplementary Materials) showed a higher signal in comparison to the sensor 3 series ( $2.0 \%$ Nafion) at the first scans which corresponds to a lower stability of the $0.2 \%$ Nafion membrane. The stability of the $2.0 \%$ Nafion membrane was also confirmed in the subsequent SEM/EDX studies of the sensor 3 and sensor 4 samples (Figure 5), obtained after CV characterization.

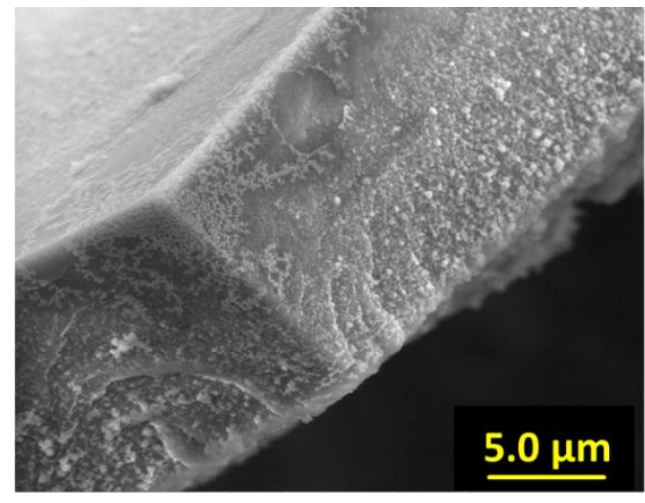

A

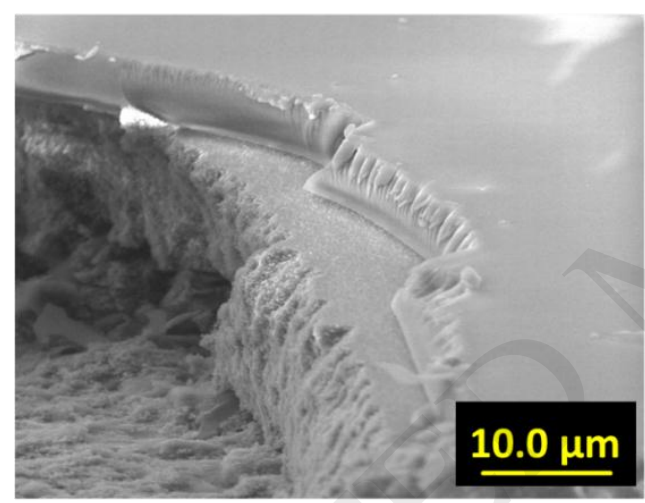

C

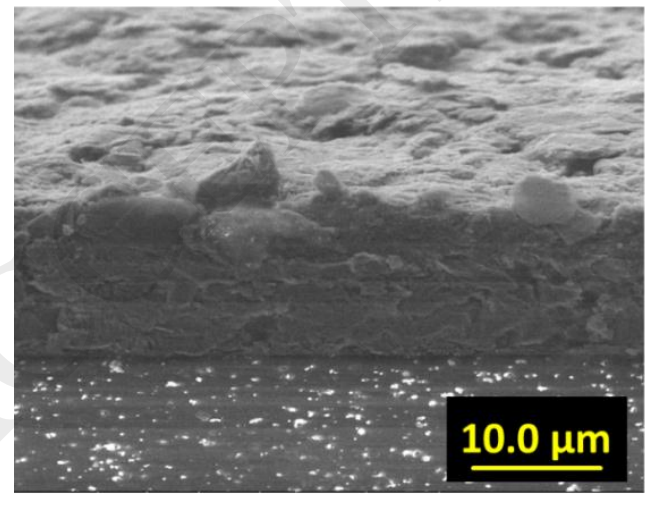

E

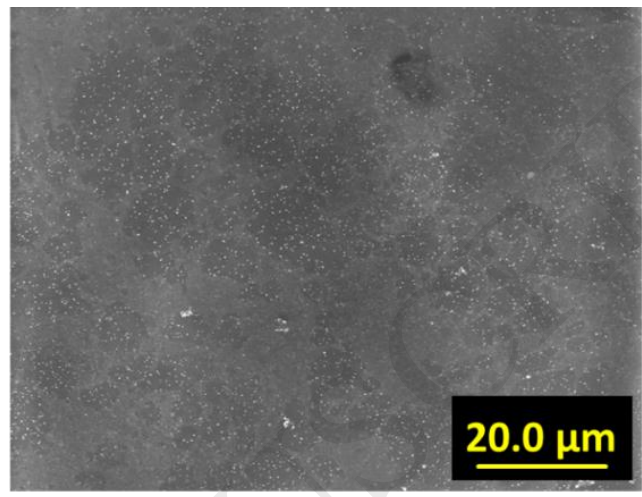

B

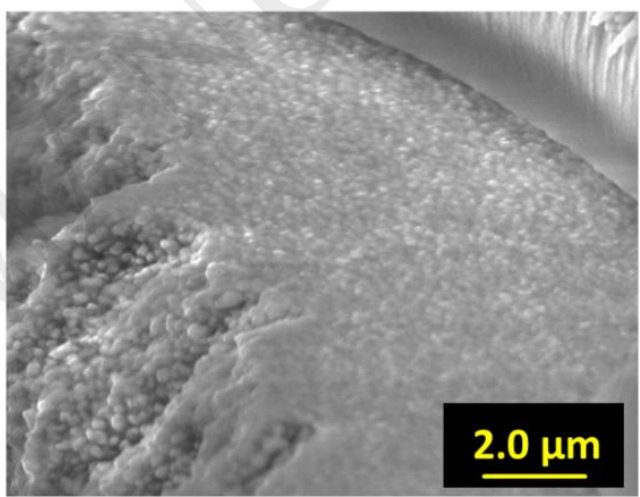

D

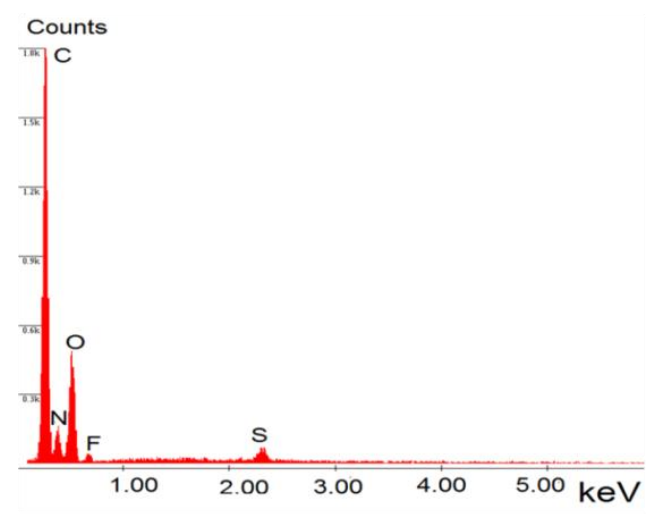

$\mathbf{F}$

Figure 5 - SEM images (A-E) and EDX spectra (F) of glucose biosensor layers. The enzyme/membrane layer of the sensor 4 series, without graphene oxide is presented in A. Top view of the enzyme/membrane layer is enlarged in B. For the sensor 3 series graphene oxide, PB and enzyme/membrane layers are shown in C. The PB layer of the sensor 3 series is enlarged in $D$, as well as a part of the enzyme/membrane layer (top right). The working electrode prior to modification steps is shown in $\mathrm{E}$. 
A non-uniform enzyme/membrane layered structure was observed in Figure $5 \mathrm{~A}$ with a dense Nafion coating on top of the surface (Figure 5B). A more detailed view on the biosensor structure for the $2.0 \%$ Nafion membrane is presented in Figure $5 \mathrm{C}$, where the graphene oxide layer with deposited Prussian Blue (Figure 5D) is covered by the enzyme/membrane film. Figure 5C clearly indicates that 2.0\% Nafion coating allows the formation of a uniform layer with final thickness equal to 5-7 $\mu \mathrm{m}$ thickness (estimated by SEM). The graphene oxide layer (top) over the plastic substrate (bottom) for commercial SPEs was demonstrated in Figure 5E. Moreover, EDX spectra taken from the enzyme/membrane film, clearly indicated the presence of Nafion, based on the fluorine and sulphur spectral lines (Figure 5F). Therefore, EDX analysis demonstrated that the Nafion layer remains fixed on the biosensor surface after performing cyclic voltammetry measurements.

\subsection{Chronoamperometric characterization of optimized biosensors}

The analytical merit of the optimized biosensors (sensor 3 series) was evaluated via chronoamperometric studies in the presence of glucose. The linear response (Figure $6 \mathrm{~A}$ ) of the constructed biosensors was obtained in the range of glucose concentrations from $10^{-3}$ to $10^{-5} \mathrm{M}$ (RSD < 7\% per electrode). The biosensors were also calibrated in the analytical range of glucose concentrations between 0.1 and $2 \mathrm{mM}$ (Figure 6B). The mean value of the slope estimated for the linear response (0 to $2 \mathrm{mM}$ ) was $-1.25 \mu \mathrm{A} / \mathrm{mM}$ with a standard deviation equal to $0.035 \mu \mathrm{A} / \mathrm{mM}$. The obtained results are in a good agreement with literature data reported for fermentation monitoring $[44,45]$.

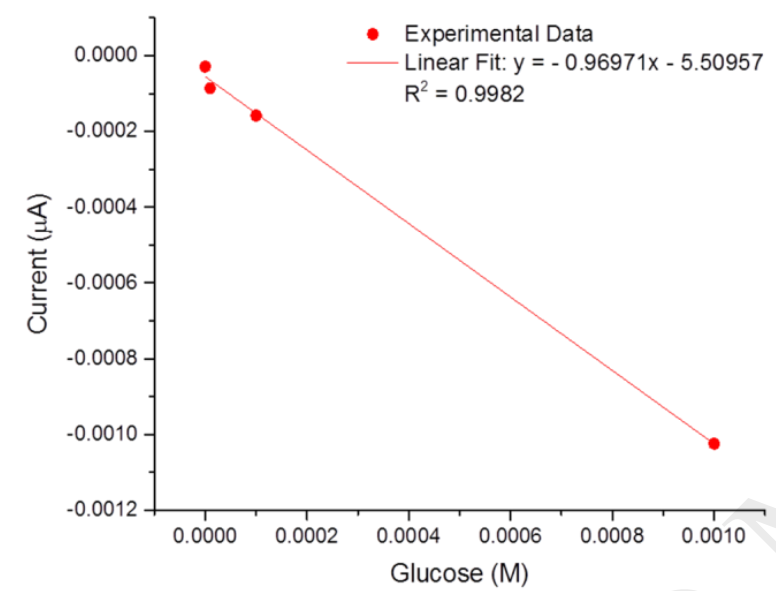

A

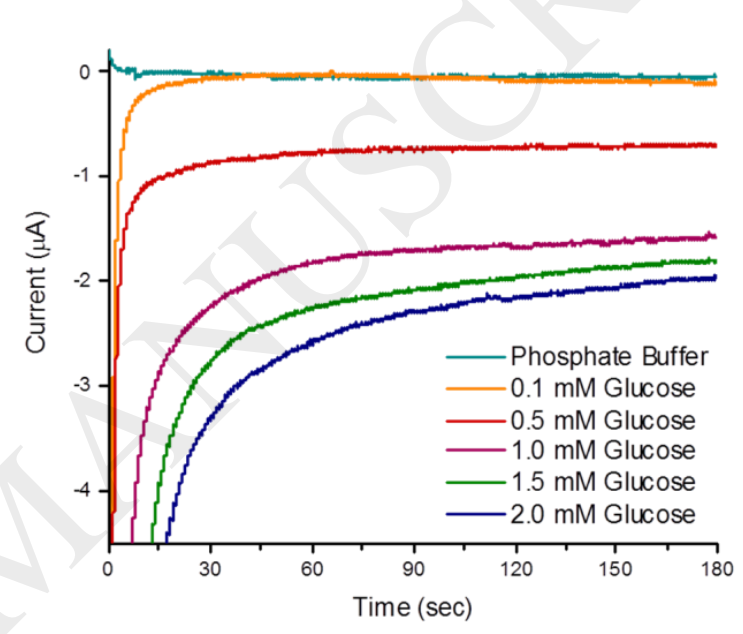

B

Figure 6 - Calibration curve (A) obtained for the optimized sensor 3 biosensors in the presence of glucose. The current response is plotted towards the glucose concentration range equal to $10^{-5}-10^{-3} \mathrm{M}$. The zero glucose concentration corresponds to the phosphate buffer solution. The relative standard deviation per electrode is not shown, due to the low value (RSD = 7\%). The chronoamperometric response (current vs time) of the analytical range of glucose concentrations is presented in B.

\section{Conclusions and Future Work}

The mathematical model of cyclic voltammetry response was developed for the glucose biosensors operating in aerobic conditions in the absence of glucose at low scan rates. The model was validated with the biosensors with various amounts of immobilized mediator and different enzyme/membrane film compositions. The biosensor system parameters required for numerical simulations were either found in literature or estimated from experimental data, therefore not limiting the applicability of the proposed model to a single biosensor design. In this work, we have demonstrated that combining the results of multi-analytical studies together with mechanistic modeling is an effective approach in identifying the key parameters of the biosensor system crucial for the optimal biosensors operation and design. Therefore, a more favorable composition of the enzyme/membrane layer ( $2.0 \%$ Nafion) was proposed and further proved to be stable at various operation conditions during cyclic voltammetry measurements.

In summary, the practical merit of the presented work is in the development of a time and cost effective tool crucial for amperometric biosensor design optimization. The demonstrated approach could potentially allow reducing the reagent usage and waste generation. As a future work, the optimized design of the glucose biosensor system will undergo further bioanalytical, morphological and amperometric studies, and the constructed model will be extended to describe the mediated enzymatic reaction of glucose oxidase in the presence of glucose. Thus, the proposed model will summarize all available process knowledge together with the results of bioanalytical and morphological analysis. Combining such model with global sensitivity and uncertainty analysis tools, will allow mapping the influence of the complete set of system input parameters on the biosensor response, which subsequently opens up the possibilities for optimization of the biosensor performance and ultimately the design of novel improved biosensors. 


\section{Acknowledgments}

This research was supported by the EUROMBR project that received funding from the People Programme (Marie Curie Actions, MultiITN) of the European Union's Seventh Framework Programme for research, technological development and demonstration under grant agreement № 608104.

The authors acknowledge Dr. Irina Petrushina, Aleksey Valerievich Nikiforov and Larisa Seerup from the Department of Energy Conversion and Storage (DTU Energy) together with Tannaz Tajsoleiman and Dr. Ulrich Krühne (PROSYS, DTU Chemical Engineering) for fruitful discussions. Moreover, the authors would like to acknowledge Dr. Claudia Fink-Straube (Chemical Analytics, INM) and the Danish Polymer Center (DPC, DTU Chemical Engineering) for their support and for providing access to their instrumentation.

\section{References}

[1] J. Wang, Electrochemical glucose biosensors, Electrochem. Sensors, Biosens. Their Biomed. Appl. (2008) 57-69. doi:10.1016/B978-012373738-0.50005-2

[2] A. Heller, B. Feldman, Electrochemical glucose sensors and their applications in diabetes management, Chem. Rev. 108 (2008) 2482-2505. doi:10.1021/cr068069y.

[3] J. Sołoducho, J. Cabaj, Electrochemical and Optical Biosensors in Medical Applications, in: T. Rinken (Ed.), Biosens. - Micro Nanoscale Appl., InTech, 2015: p. 466. doi:10.5772/711.

[4] M.S. Belluzo, M.É. Ribone, C.M. Lagier, Assembling Amperometric Biosensors for Clinical Diagnostics, Sensors. 8 (2007) 1366 1399. doi:10.3390/s8031366.

[5] A.M. Gonçalves, A.Q. Pedro, F.M. Santos, L.M. Martins, C.J. Maia, J.A. Queiroz, L.A. Passarinha, Trends in protein-based biosensor assemblies for drug screening and pharmaceutical kinetic studies, Molecules. 19 (2014) 12461-12485. doi:10.3390/molecules190812461.

[6] M.A. Alonso-Lomillo, O. Domínguez-Renedo, M.J. Arcos-Martínez, Screen-printed biosensors in microbiology; A review, Talanta. 82 (2010) 1629-1636. doi:10.1016/j.talanta.2010.08.033.

[7] L.D. Mello, L.T. Kubota, Review of the use of biosensors as analytical tools in the food and drink industries, Food Chem. 77 (2002) 237-256. doi:10.1016/S0308-8146(02)00104-8.

[8] B.M. Paddle, Biosensors for chemical and biological agents of defence interest, Biosens. Bioelectron. 11 (1996) $1079-1113$. doi:10.1016/0956-5663(96)82333-5.

[9] J.M. Montornes, M.S. Vreeke, I. Katakis, Glucose Biosensors, Bioelectrochemistry Fundam. Exp. Tech. Appl. (2008) $199-217$. doi:10.1002/9780470753842.ch5.

[10] J. Shi, D. Feng, Y. Li, Biosensors in Fermentation Applications, in: A.F. Jozala (Ed.), Ferment. Process., InTech, 2017 : p. 310. doi:10.5772/711.

[11] D. Grieshaber, R. Mackenzie, J. Vörös, E. Reimhult, Electrochemical Biosensors -Sensor Principles and Architectures, Sensors. 8 (2008) 1400-1458. doi:10.3390/s8031400.

[12] R. Baronas, F. Ivanauskus, J. Kulys, Mathematical Modeling of Biosensors An Introduction for Chemists and Mathematicians, Springer Netherlands, 2010. doi:10.1007/b100321.

[13] L.D. Mell, J.T. Maloy, Model for the amperometric enzyme electrode obtained through digital simulation and applied to the immobilized glucose oxidase system, Anal. Chem. 47 (1975) 299-307. doi:10.1021/ac60352a006.

[14] G.G. Guilbault, G.J. Lubrano, An enzyme electrode for the amperometric determination of glucose, Anal. Chim. Acta. 64 (1973) 439-455. doi:10.1016/S0003-2670(01)82476-4.

[15] R.S. Nicholson, I. Shain, Theory of Stationary Electrode Polarography: Single Scan and Cyclic Methods Applied to Reversible Irreversible, and Kinetic Systems, Anal. Chem. 36 (1964) 706-723. doi:10.1021/ac60210a007.

[16] M. Rudolph, D.P. Reddy, S.W. Feldberg, A simulator for cyclic voltammetric responses, Anal. Chem. 66 (1994) 589A-600A.

[17] K. Yokoyama, Y. Kayanuma, Cyclic Voltammetric Simulation for Electrochemically Mediated Enzyme Reaction and Determination of Enzyme Kinetic Constants, Anal. Chem. 70 (1998) 3368-3376. doi:10.1021/ac9711807. 
[18] K. Yokoyama, S. Koide, Y. Kayanuma, Cyclic voltammetric simulation of electrochemically mediated enzyme reaction and elucidation of biosensor behaviors., Anal. Bioanal. Chem. 372 (2002) 248-53. doi:10.1007/s00216-001-1203-9.

[19] M. Orlik, An improved algorithm for the numerical simulation of cyclic voltammetric curves affected by the ohmic potential drops and its application to the kinetics of bis(biphenyl)chromium(I) electroreduction, J. Electroanal. Chem. 575 (2005) 281-286. doi:10.1016/j.jelechem.2004.10.001.

[20] Z. Deng, X. Lin, Digital simulation of fast cyclic voltammogram by integration of the double layer charging current, J. Electroanal. Chem. 464 (1999) 215-221.

[21] H. Cho, T. Kim, D. Yoon, A study on the computational simulation of cyclic voltammetry using semi-infinite diffusion model, J. Korean Electrochem. Soc. 14 (2011) 138-144.

[22] B.J. Adesokan, X. Quan, A. Evgrafov, M.P. Sørensen, A. Heiskanen, A. Boisen, Hydrodynamics studies of cyclic voltammetry for electrochemical micro biosensors, J. Phys. Conf. Ser. 574 (2015) 12008. doi:10.1088/1742-6596/574/1/012008.

[23] B.J. Adesokan, X. Quan, A. Evgrafov, A. Heiskanen, A. Boisen, M.P. Sørensen, Experimentation and numerical modeling of cyclic voltammetry for electrochemical micro-sized sensors under the influence of electrolyte flow, J. Electroanal. Chem. 763 (2016) 141-148. doi:10.1016/j.jelechem.2015.12.029.

[24] M.J. Bidwell, J.A. Alden, R.G. Compton, Hydrodynamic voltammetry with channel microband electrodes: The simulation of voltammetric waveshapes, J. Electroanal. Chem. 417 (1996) 119-128. doi:10.1016/S0022-0728(96)04739-0.

[25] D. Pletcher, R. Greef, R. Peat, L.M. Peter, J. Robinson, Instrumental methods in Electrochemisty, Woodhead Publishing Limited, Cambridge, 2011. doi:http://dx.doi.org/10.1016/B978-0-12-525440-3.50002-X.

[26] C. Cannes, F. Kanoufi, A.J. Bard, Cyclic voltammetry and scanning electrochemical microscopy of ferrocenemethanol at monolayer and bilayer-modified gold electrodes, J. Electroanal. Chem. 547 (2003) 83-91. doi:10.1016/S0022-0728(03)00192-X.

[27] C. Cannes, F. Kanoufi, A.J. Bard, Cyclic voltammetric and scanning electrochemical microscopic study of menadione permeability through a self-assembled monolayer on a gold electrode, Langmuir. 18 (2002) 8134-8141. doi:10.1021/la0258906.

[28] F. Ricci, A. Amine, C.S. Tuta, A.A. Ciucu, F. Lucarelli, G. Palleschi, D. Moscone, Prussian Blue and enzyme bulk-modified screenprinted electrodes for hydrogen peroxide and glucose determination with improved storage and operational stability, Anal. Chim. Acta. 485 (2003) 111-120. doi:10.1016/S0003-2670(03)00403-3.

[29] F. Ricci, A. Amine, G. Palleschi, D. Moscone, Prussian Blue based screen printed biosensors with improved characteristics of long-term lifetime and pH stability, Biosens. Bioelectron. 18 (2003) 165-174.

[30] A.N. Sekretaryova, M. Eriksson, A.P.F. Turner, Bioelectrocatalytic systems for health applications, Biotechnol. Adv. 34 (2016) 177197. doi:10.1016/j.biotechadv.2015.12.005.

[31] R.C. Cretu, D.M. Gligor, L. Muresan, I.C. Popescu, L.M. Muresan, Kinetic characterization of Prussian Blue-modified graphite electrodes for amperometric detection of hydrogen peroxide, J. Appl. Electrochem. 36 (2006) 1327-1332. doi:10.1007/s10800006-9242-8.

[32] K. Itaya, N. Shoji, I. Uchida, Catalysis of the reduction of molecular oxygen to water at Prussian blue modified electrodes, J. Am. Chem. Soc. 106 (1984) 3423-3429. doi:10.1021/ja00324a007.

[33] P. Gros, A. Bergel, Improved model of a polypyrrole glucose oxidase modified electrode, J. Electroanal. Chem. 386 (1995) 65-73. doi:10.1016/0022-0728(94)03804-C.

[34] S.C. Barton, Chapter 8: Enzyme catalysis in biological fuel cells, in: W. Vielstich, H.A. Gasteiger, A. Lamm, H. Yokokawa (Eds.), Handb. Fuel Cells - Fundam. Technol. Appl., John Wiley \& Sons, Ltd, 2010: pp. 1-19.

http://www.wiley.com/WileyCDA/WileyTitle/productCd-0470723114.html.

[35] H.C. Chang, C.C. Wu, S.J. Ding, I.S. Lin, I.W. Sun, Measurement of diffusion and partition coefficients of ferrocyanide in proteinimmobilized membranes, Anal. Chim. Acta. 532 (2005) 209-214. doi:10.1016/j.aca.2004.10.063.

[36] K. Itaya, K. Shibayama, H. Akahoshi, S. Toshima, Prussian-blue-modified electrodes: An application for a stable electrochromic display device, J. Appl. Phys. 53 (1982) 804-805. doi:10.1063/1.329997.

[37] K. Itaya, H. Akahoshi, S. Toshima, Electrochemistry of Prussian Blue Modified Electrodes: An Electrochemical Preparation Method, J. Electrochem. Soc. 129 (1982) 1498-1500. doi:10.1149/1.2124191. 
[38] J. Kulys, R. Vidziunaite, Laccase based synergistic electrocatalytical system, Electroanalysis. 21 (2009) 2228-2233. doi:10.1002/elan.200904679.

[39] M. Mahosenaho, F. Caprio, L. Micheli, A.M. Sesay, G. Palleschi, V. Virtanen, A disposable biosensor for the determination of alpha-amylase in human saliva, Microchim. Acta. 170 (2010) 243-249. doi:10.1007/s00604-010-0360-y.

[40] J.M. Bolivar, T. Consolati, T. Mayr, B. Nidetzky, Quantitating intraparticle O2 gradients in solid supported enzyme immobilizates: Experimental determination of their role in limiting the catalytic effectiveness of immobilized glucose oxidase, Biotechnol. Bioeng. 110 (2013) 2086-2095. doi:10.1002/bit.24873.

[41] J.M. Bolivar, S. Schelch, M. Pfeiffer, B. Nidetzky, Intensifying the O2-dependent heterogeneous biocatalysis: superoxygenation of solid support from $\mathrm{H} 2 \mathrm{O} 2$ by a catalase tailor-made for effective immobilization, J. Mol. Catal. B Enzym. 134 (2016) 302-309. doi:http://dx.doi.org/10.1016/j.molcatb.2016.10.017.

[42] D.A. Ellis, S.A. Mabury, J.W. Martin, D.C.G. Muir, Thermolysis of fluoropolymers as a potential source of halogenated organic acids in the environment., Nature. 412 (2001) 321-324. doi:10.1038/35085548.

[43] M. Feng, R. Qu, Z. Wei, L. Wang, P. Sun, Z. Wang, Characterization of the thermolysis products of Nafion membrane: A potential source of perfluorinated compounds in the environment, Sci. Rep. 5 (2015) 9859. doi:10.1038/srep09859.

[44] S.F. White, I.E. Tothill, J.D. Newman, A.P.F. Turner, Development of a mass-producible glucose biosensor and flow-injection analysis system suitable for on-line monitoring during fermentations, Anal. Chim. Acta. 321 (1996) 165-172. doi:10.1016/00032670(95)00514-5.

[45] A.C. Fernandes, D. Semenova, P. Panjan, A.M. Sesay, K. V Gernaey, U. Krühne, Multi-function microfluidic sensor integration platform for sensors integration, N. Biotechnol. In press (n.d.). 


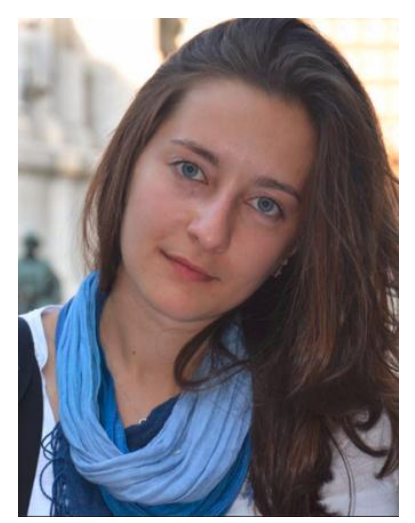
synthetic bioactive substances from D. Mendeleev University of Chemical Technology of Russia in 2012. She worked as a researcher on modifications of natural alkaloids and synthesis of novel fluorinated thebaine derivatives in the Laboratory of Fine Organic Synthesis at A.N. Nesmeyanov Institute of Organoelement Compounds (INEOS) Russian Academy of Sciences until 2014. Since August 2014 she has been working toward her PhD degree at the Process and Systems Engineering Center (PROSYS), at the Chemical and Biochemical department at the Technical University of Denmark (DTU). Her current research interests are focused on the development of the mathematical models for the design and optimization of screening technologies for bio-based processes.

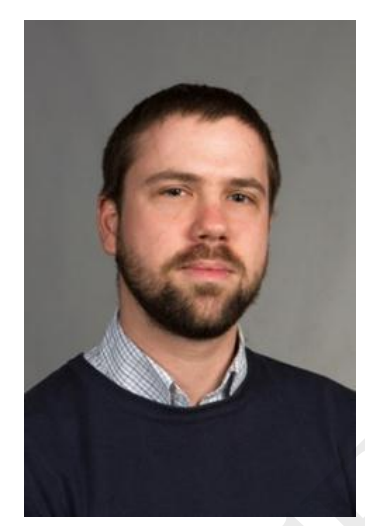

Alexandr Zubov received PhD in Chemical Engineering in 2014 from the University of Chemistry and Technology Prague. Until 2015 he worked there as a research assistant and assistant professor in the Group of Polymer Reaction Engineering led by Prof. Juraj Kosek. Since October 2015 he is employed as a postdoc at the Technical University of Denmark. His research interests include mathematical modelling of multi-phase reactors, dynamic transport in hetero-phase media, model-based optimization and control of industrial processes, and mathematical morphology. 


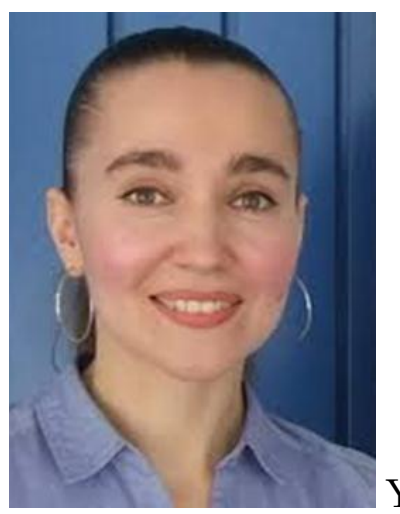

Yuliya E. Silina has completed her PhD in Analytical Chemistry in 2005 (Voronezh State University of Engineering Technology, Russia). Currently, she is a principal investigator of a team focusing on developments in the modern mass spectrometry, lab-on-achip devices, bio- and environmental sensing at INM - Leibniz Institute of New Materials (Saarbrücken, Germany). She has published more than 30 papers in reputed journals and holds 11 patients for her inventions.

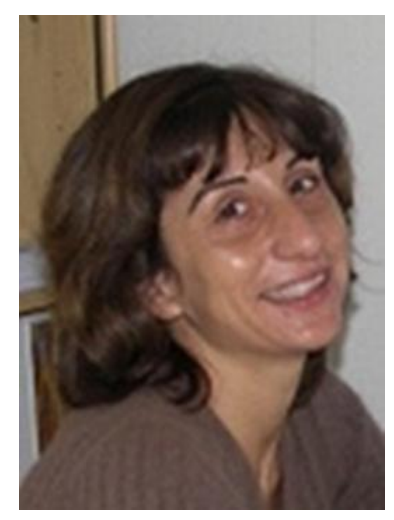

Laura Micheli is an associate professor in analytical chemistry at the department of Chemical Science and Technologies at the Università di Roma Tor Vergata (Italy). The research activities of Prof. Micheli are focused on the study and development of disposable electrochemical tools for the determination of several analytes in food, clinical and cultural heritage fields, by use of spectrophotometric and chromatographic methods. Here research interests include the development of immunosensors, interference-free biosensors based on screen printed electrodes (SPEs), as well as novel techniques and tools for biosensor platform integration. She collaborates with the research group CEMIS-OULU (University of Oulu, Finland) and private companies (EUROLAB srl, 2005-2010, Systea S.p.A., 2012-now). 


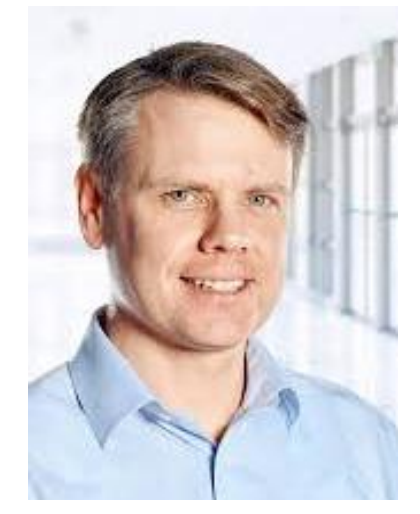

Marcus Koch has received his $\mathrm{PhD}$ in Physics in 2004 (Saarland University, Germany). In June 2000 he started working at INM - Leibniz Institute of New Materials (Saarbrücken, Germany) in the group of electron microscopy and X-ray diffraction. Since January 2015 he's leader of the group Physical Analytics at INM. His main research interests are correlative and environmental electron microscopy of nanostructured samples.

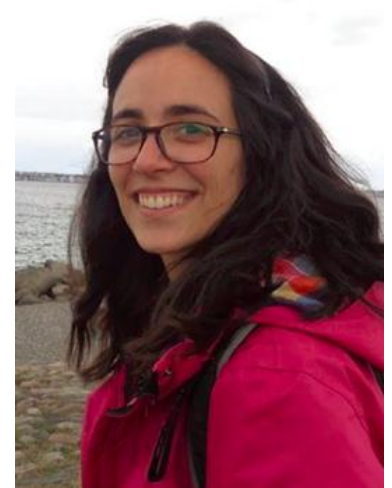

Ana C. Fernandes graduated in 2012 in Biological Engineering from the Technical University of Lisbon (Portugal). She worked as a researcher in microfluidics and integration of magnetic sensors towards health applications at INESC-Microsystems and Nanotechnology in Lisbon (Portugal) until 2014. In June 2014 she started her PhD at the Process and Systems Engineering Center (PROSYS), at the Chemical and Biochemical department at the Technical University of Denmark (DTU) with Adama M. Sesay, Krist Gernaey and Ulrich Krühne.

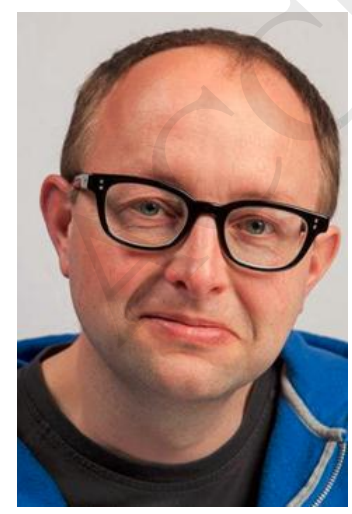

Krist V. Gernaey holds a PhD degree in Applied Biological Sciences from Ghent University (Belgium) since 1997. He is professor in industrial fermentation technology at the Department of Chemical and Biochemical Engineering, Technical University of 
Denmark (DTU) since 2013. He is head of the Process and Systems Engineering Center (PROSYS), and CEO of the startup company Bioscavenge. He has been a postdoctoral fellow at Ghent University, Ecole Polytechnique de Montreal, DTU and Lund University (1998-2005), and associated professor at DTU Chemical Engineering since 2005. His current research interests are large-scale fermentation, modelling and process simulation, scaling up/down and resource recovery processes. 